\title{
Parenting Styles as Determinants of Psychopathological Symptoms among Nigerian In-School Adolescents
}

\author{
Onyekachukwu Oyindamola Aniemeka1, Ebenezer Olutope Akinnawo1, \\ Aderonke Adebola Akintola ${ }^{1}$, Bede Chinonye Akpunne ${ }^{1^{*}} \mathbb{E}^{\mathbb{D}}$, Daniel Olawasanmi Kumuyi ${ }^{1}$, \\ Deborah Foluke Onisile ${ }^{2}$ \\ ${ }^{1}$ Department of Behavioural Studies, Faculty of Social Sciences, Redeemers' University, Ede, Osun State, Nigeria \\ ${ }^{2}$ Department of Nursing Science, Faculty of Basic Medical Sciences, Redeemers' University, Ede, Osun State, Nigeria \\ Email: ^akpunneb@run.edu.ng
}

How to cite this paper: Aniemeka, O. O., Akinnawo, E. O., Akintola, A. A., Akpunne, B. C., Kumuyi, D. O., \& Onisile, D. F. (2021). Parenting Styles as Determinants of Psychopathological Symptoms among Nigerian In-School Adolescents. Psychology, 12, 959-975.

https://doi.org/10.4236/psych.2021.126058

Received: May 18, 2021

Accepted: June 27, 2021

Published: June 30, 2021

Copyright $\odot 2021$ by author(s) and Scientific Research Publishing Inc. This work is licensed under the Creative Commons Attribution International License (CC BY 4.0).

http://creativecommons.org/licenses/by/4.0/

(c) (i) Open Access

\begin{abstract}
The controversy concerning the extent to which parental influence matters to children's psychological and behavioural growth continues. This study investigated the influence of parenting styles on psychopathological symptoms among in-school adolescents in Ogun State, South-western Nigeria. A cross-sectional survey design method was utilized. One thousand and twenty-eight (1028) in-school adolescents with mean age \pm SD of $15.30 \pm 2.14$, were drawn from ten secondary schools, and these responded to the Awaritefe Psychological Index (API) Form X, and the Scales for Parenting Style (SPS). A $52.1 \%$ prevalence of psychopathological symptoms was observed. A significant mean score difference was found between negligent parenting style and authoritarian parenting style in determining severities of psychopathological symptoms among adolescents. Responsive and control dimension of parenting style jointly predicted psychopathological symptoms $\left(\mathrm{R}^{2}=0.01\right.$, $\mathrm{F}(2,1025)=4.36, p<0.01)$. Gender significantly influenced general psychopathology $[\mathrm{t}(1026)=2.27 ; p<0.05]$. The family type also had a significant influence on psychopathological symptoms. Participants from polygamous family setting reported higher psychopathological symptoms $[\mathrm{t}(1026)=$ $-2.78, p<0.01]$ than those from polygamous family settings. A balance between the control parenting style and the responsive parenting style is recommended.
\end{abstract}

\section{Keywords}

Parenting Styles, Psychopathological Symptoms, In-School Adolescents, Nigeria 


\section{Introduction}

The World Health Organization (WHO) at the International Health Conference held in New York, USA, in 1946 defined health as not only the absence of illness but a complete state of mental, physical and social well-being (International Health Conference, 1946). Kolappa et al. (2013) emphasized the multidimensional nature of health and the impact of mental health in determining overall well-being. Child health cannot be excluded in this regard, as Patel and Rahman (2015) pointed out the relevance of child mental health to global health.

According to epidemiological studies, the worldwide-pooled prevalence of psychopathology in children and adolescents is around $13.4 \%$, so it can be asserted that mental disorders affect a significant number of youths worldwide (Polanczyk, Salum, Sugaya, Caye, \& Rohde, 2015). Folkehelseinstituttet (2014) further reported that at any given time, approximately $15 \%-20 \%$ of all children and adolescents experience psychological strain, with symptoms compromising their well-being, everyday tasks, learning, and interactions with others. Awaritefe et al. (2010) highlighted various psychopathological symptoms. These include disordered sleep (excess sleep and problems with achieving or maintaining sleep), intellect disorder (thought blocks, low concentration and illusions) and psychosomatic issues (Awaritefe et al., 2010). Other psychopathological symptoms are heat disorders (heat in the head, warmth in the stomach, peppery sensation in the head and pepperiness around the body), mood disorder (depression, bipolar disorders, Disruptive mood dysregulation disorder (DMDD) and cyclothymic disorder) and head region disorder (frequent headaches, heavy sensation in the head, knocking sensation in the head and pain in the neck). Other psychopathological symptoms are manifest as disorders in the alimentary tract (decreased appetite, constipation, stomach pain, vomiting and so on) and general somatic disorder (fatigue, body-wide pain, waist pain, rapid heart beating or jumping, back pain, and so on (Awaritefe et al., 2010).

Brooks et al. (2012) attributed some child psychopathology to parenting-related issues. Parenting involves nurturing, instructing, directing, controlling and disciplining the children in preparation for their role in society in general and in personal life. Parenting style is a psychological construct representing standard strategies parents use in their child or children (Spera, 2005). Parenting styles are critical family context factors closely related to parent-adolescent relationships (Nelson et al., 2011). Earlier research has shown that diverse parenting styles contribute to varying outcomes in child care, psychosocial skills, and environmental demands in child progress (You \& Lim, 2015). In parental control, youth's social, emotional, and mental growth was established as a significant dimension of parenting (Maccoby \& Martin, 1983). In parenting, Maccoby \& Martins (1983) and Baumrind's (1991) typological approach of conceptualizing parenting has had a tremendous impact. They classified parenting into four types based on responsiveness and demandingness (Maccoby \& Martin, 1983; Baumrind, 1991). These four styles of parenting include; authoritative, authoritarian, 
permissive and uninvolved parenting style.

Authoritative parents are high in warmth and firm in control. They support the freedom of children but also restrict and track their behaviour. Children with authoritative parents are always happy self-regulated, self-conform, and achievement-oriented in a relaxed manner (Baumrind, 1991). Authoritarian parents are defined as rigid, punitive and demand unquestioning obedience from their children. They have stringent standards and discourage expressions of disagreement (Maccoby \& Martin, 1983; Baumrind, 1991). Permissive parents are warm, yet they require little from their children. Hence they give their children law or inconsistent directions. The uninvolved parenting style is said to have the most negative impact in contrast with the other three parenting types on teenage outcomes. Parents without involvement often fail to control or monitor the actions of their children and do not encourage or facilitate the self-regulation of their children. The uninvolved parenting style is described as low reactivity and low demand (Maccoby \& Martin, 1983; Baumrind, 1991).

Li, Wang and Zhang (2012) and Verhoeven et al. (2012) reported that poor parenting style would increase children's psychological problems. Adolescents with better mental health are said to be physically healthier, demonstrate more socially positive behaviours, and engage in fewer risky behaviours (Resnick et al., 1997). Also, according to Ruchkin et al. (2000), there is a significant connection between parenting styles and a child's psychopathology. Perris (1994) indicates that poor relationships with the parents contribute to psychopathology symptoms in the same line of finding.

Scholars like Li, Wang and Zhang (2012) and Verhoeven et al. (2012) have reported that poor parenting style would increase children's psychological problems. In regard to adolescents' mental health, the longitudinal study of (Chen \& Harris, 2019) showed that positive family relationships are associated with better mental health. Also, according to (Bolghan-Abadi et al., 2011) there is a significant connection between parenting styles and a child's psychopathology. Landstedt et al. (2015) indicates that poor relationships with the parents contribute to psychopathology symptoms.

Attachment theory provides a compelling model for the investigation of psychological development as a function of co-constructed parent-child relationship quality (Bowlby, 1980), offering a lens through which to understand parent-child convergence. Emerging from parent-infant interactions is a set of implicit rules, called an internal working model of attachment (IWM; Bowlby, 1980). The child learns about the self, relationships, and the world with considerable developmental continuity. Parental responsiveness to infant needs results in attachment security, the internalized confidence that attachment figure(s) will be psychologically and physically available, whereas inconsistent or unresponsive parental care results in an insecure IWM (Bowlby, 1969). In a study by (Nakash-Eisikovits et al., 2002), insecure parental attachment was considered a determinant of psychopathology in later stages of life. In contrast, the secure attachment was linked to healthy processes. 
This study aims to determine the predictive influence of parenting styles on psychopathological symptoms among in-school adolescents in Ogun State, southwestern Nigeria.

\section{Hypotheses}

1) Parenting styles will significantly predict psychopathological symptoms among in-school adolescents in Ogun State.

2) There will be a significant gender difference in psychopathological symptom among in-school adolescents in Ogun State.

3) There will be a significant influence of family type on psychopathological symptoms among in-school adolescents in Ogun state.

\section{Methods and Materials}

\subsection{Research Design}

A cross-sectional survey research design was adopted in this study. A multi-stage sampling technique was employed in selecting in-school adolescents from five Local Governments Areas in Ogun State, Nigeria. The first stage involved simple random sampling in selecting five out of the twenty Local Governments Areas in Ogun State. A random sampling technique was equally used in selecting two secondary schools made up of a public and a privately owned school in each local Government. Finally, a total of one hundred students were purposively selected across different classes and gender in each of the schools. The researchers monitored the data collection process to avoid errors. The Principal of each of the schools were approached with a letter from the educational board in Ogun State introducing the researchers and the research assistants. The questionnaires were administered only to students in both Junior and Senior Secondary School classes. The researchers introduced themselves and the purpose of the study, explaining that the research was voluntary and confidential. After this exercise, the questionnaires were administered to the students. Some students who declined were permitted to leave the class. The researchers read out items and clarified words or phrases for some students who had difficulty completing the tests. The duration of the administration of the tests was between 20 - 30 minutes per student. Class teachers assisted in some schools with the administration of the tests, that is, distributing the test packets and calling the attention of the principal investigator to any child who required assistance with completing the test. Two days was spent in each school and a total of two weeks for the entire duration. Of the one-thousand five hundred questionnaires distributed in the selected schools, one thousand three hundred and thirty (1330) were retrieved. One thousand and twenty-eight (1028) were found valid and used for data analysis.

\subsection{Research Instruments}

For this study, two standardized instruments were used for data collection: the Awaritefe Psychological Index (API Form X) (Awaritefe, 1982) and the Scale of 
Parenting Style (SPS). The API measures psychopathological symptoms among participants. It is a 76 item scale consisting of seven subscales (sleep disorder, intellect disorder, heat disorder, mood disorder, head region disorder, alimentary tract disorder and general somatic disorders). API is measured on a 3-point Likert scale response categories of "Yes" = 2, "No" = 1 and "?" = 0 . The higher the scores in the subscales and total score, the higher the level of psychopathology reported by the respondent and the lower the scores, the better the psychological health status. API (Form X) has a reliability coefficient Cronbach of 0.87 , a retest reliability coefficient of 0.86 for males and 0.80 for females at a 21-day interval. The instrument also has a split-half reliability coefficient of $0.85(\mathrm{~N}=$ $250, p=0.000$ ) (Akinnawo, 1990) and a Guttman slit-half reliability coefficient of 6.63 (Akinnawo \& Ofovwe, 2012). API has a significant positive relationship with the neuroticism dimension of the Maudsley Personality Inventory (MPI), the Beck Depression Inventory and the General Health Questionnaire (GHQ-12) (Akinnawo, 1990; Akinnawo \& Ofovwe, 2012).

The second instruments used in this study is the Scale of Parenting Style, developed by Abdul Gafoor and Abidha (2014). It is a-38 item scale scored on 5 -point Likert format, ranging from "Very right" $=5$, "Mostly right" $=4$, "Sometimes right, Sometimes wrong" $=3$, "Mostly wrong" $=2$, and "Very wrong" $=1$. SPS has a validity coefficient of 0.80 for responsiveness and 0.76 for the control subscale (Abdul Gafoor \& Abidha, 2014). The reliability of SPS was established by the test-retest method after a one-week interval. The test-retest coefficient of reliability of responsiveness and control dimensions of the scale is 0.81 and 0.83 , respectively. A pilot study by the authors yielded Cronbach's alpha coefficient of 0.940 , indicating that the parenting styles scale is reliable among the sampled population.

\subsection{Data Analysis}

Data collected was analyzed using Statistical Package for Social Sciences (SPSS) version 23. Descriptive and inferential statistics was used in this study. The demographic characteristics, patterns, and prevalence of parenting styles and psychopathological symptoms were analyzed using descriptive statistics (frequency counts and simple percentages). One way Analysis of variance (ANOVA), regression analysis and independents sample t-test were used to test hypotheses in this study.

\section{Results}

Table 1 shows the pattern and prevalence of psychopathological symptoms among in-school adolescents. It was revealed that there was a total of $45.6 \%$ prevalence rate of sleep disorder, made up of $31.1 \%$ of the participants were at the mild to moderate level, and $14.5 \%$ at moderate to severe levels. The pattern of intellect disorder showed that $21.6 \%$ were at the mild to moderate level, while $24 \%$ reported moderate to severe level. $33.6 \%$ mild-moderate and $20.8 \%$ moderate-severe prevalence of heat disorder was also reported. Furthermore, 35.1\% 
Table 1. Showing frequency and patterns of psychopathological symptoms among in-school adolescents in Ogun state, Nigeria.

\begin{tabular}{cccc}
\hline Psychopathological Symptoms & \multicolumn{3}{c}{ Prevalence (\%) } \\
\hline Nil & Mild to Moderate & Moderate to Severe \\
\hline Intellect Disorder & 54.4 & 31.1 & 14.5 \\
Heat Disorder & 54.4 & 21.6 & 24 \\
Mood Disorder & 45.6 & 33.6 & 20.8 \\
Head Region Disorder & 49.8 & 35.1 & 15.1 \\
Alimentary Tract Disorder & 52.0 & 32.1 & 15.9 \\
General Somatic Disorder & 49.7 & 32.1 & 18.2 \\
General Psychopathology & 51.1 & 28.4 & 20.1 \\
\hline
\end{tabular}

and $15.1 \%$ prevalence of mild-moderate and moderate-severe levels respectively of mood disorder, $32.1 \%$ and $15.9 \%$ prevalence of head region disorder at the mild-moderate and moderate-severe levels respectively, $2.1 \%$ and $19.9 \%$ prevalence of alimentary track disorder at the mild-moderate and moderate-severe levels respectively was reported among the adolescents. Table 1 reveals further that there was $28.4 \%$ and $20.1 \%$ prevalence of general somatic disorder at the mild-moderate and moderate-severe levels respectively, and finally, $39.0 \%$ and $13.1 \%$ prevalence of general psychopathology at the mild-moderate and moderate-severe levels respectively was reported among the adolescents

Table 2 shows the pattern of parenting styles among in-school adolescents. There was a $41.9 \%$ and a $58.1 \%$ prevalence of responsive parenting at the low and high levels, respectively. In addition, control parenting had 39.6\% and $60.4 \%$ at low and high levels. The prevalence rate of neglectful parenting style was $31.7 \%$, permissive parenting style had $7.9 \%$, authoritarian parenting style $10.2 \%$ and authoritative parenting style had $50.2 \%$.

The descriptive analysis and post-hoc analysis summarized in Table 3 showed that students from authoritarian parenting styles significantly reported a high level of heat disorder than those from negligent, permissive, and authoritative parenting styles.

As summarized in Table 4, parenting styles significantly influenced heat disorder $[\mathrm{F}(3,1024)=4.15, p<0.01]$ among the participants. However it was observed that parenting styles had no significant influence on sleep disorder $[\mathrm{F}(3$, $1024)=0.50, p>0.05]$, intellect disorder $[\mathrm{F}(3,1024)=1.09, p>0.05]$, mood disorder $[\mathrm{F}(3,1024)=2.13, p>0.05]$, head region disorder $[\mathrm{F}(3,1024)=1.00$, $p>0.05]$, alimentary tract $[\mathrm{F}(3,1024)=1.53, p>0.05]$, general somatic $[\mathrm{F}(3$, $1024)=2.18, p>0.05]$ and general psychopathology $[\mathrm{F}(3,1024)=2.51, p>$ 0.05].

The result in Table 5 indicated a significant mean score difference between negligent parenting style and authoritarian parenting style (mean $=1.36, p<0.05$ ). 
O. O. Aniemeka et al.

Table 2. Descriptive statistics showing pattern of parenting style among in-school adolescents.

\begin{tabular}{|c|c|c|c|c|c|c|}
\hline \multirow{2}{*}{ Parenting Style } & \multirow{2}{*}{ Range } & \multirow{2}{*}{ Mean } & \multirow{2}{*}{ SD } & \multicolumn{3}{|c|}{ Prevalence $(\mathrm{N}=1028)$} \\
\hline & & & & Rating & F & $\%$ \\
\hline \multirow{2}{*}{ Responsive Parenting } & \multirow{2}{*}{$19-95$} & \multirow{2}{*}{78.89} & \multirow{2}{*}{12.20} & Low & 431 & 41.9 \\
\hline & & & & High & 597 & 58.1 \\
\hline \multirow{2}{*}{ Control Parenting } & \multirow{2}{*}{$19-95$} & \multirow{2}{*}{79.93} & \multirow{2}{*}{12.87} & Low & 407 & 39.6 \\
\hline & & & & High & 621 & 60.4 \\
\hline \multirow{4}{*}{ Parenting Style } & \multirow{4}{*}{-} & \multirow{4}{*}{-} & \multirow{4}{*}{-} & Negligent & 326 & 31.7 \\
\hline & & & & Permissive & 81 & 7.9 \\
\hline & & & & Authoritarian & 105 & 10.2 \\
\hline & & & & Authoritative & 516 & 50.2 \\
\hline
\end{tabular}

Table 3. Mean and standard deviation showing the difference in styles of parenting on psychopathological symptoms.

\begin{tabular}{|c|c|c|c|c|}
\hline Psychopathological Symptoms & Parenting Style & $\mathbf{N}$ & Mean & Std. Deviation \\
\hline & Negligent & 326 & 8.33 & 2.226 \\
\hline & Permissive & 81 & 8.41 & 1.752 \\
\hline \multirow[t]{5}{*}{ Sleep Disorder } & Authoritarian & 105 & 8.10 & 1.599 \\
\hline & Authoritative & 516 & 8.24 & 2.004 \\
\hline & Total & 1028 & 8.27 & 2.021 \\
\hline & Negligent & 326 & 5.49 & 1.812 \\
\hline & Permissive & 81 & 5.33 & 1.323 \\
\hline \multirow[t]{5}{*}{ Intellect Disorder } & Authoritarian & 105 & 5.20 & 1.403 \\
\hline & Authoritative & 516 & 5.39 & 1.340 \\
\hline & Total & 1028 & 5.40 & 1.511 \\
\hline & Negligent & 326 & 13.43 & 3.958 \\
\hline & Permissive & 81 & 12.99 & 2.935 \\
\hline \multirow[t]{5}{*}{ Heat Disorder } & Authoritarian & 105 & 12.08 & 2.460 \\
\hline & Authoritative & 516 & 13.07 & 3.320 \\
\hline & Total & 1028 & 13.07 & 3.452 \\
\hline & Negligent & 326 & 34.41 & 8.105 \\
\hline & Permissive & 81 & 33.64 & 6.305 \\
\hline \multirow[t]{5}{*}{ Mood Disorder } & Authoritarian & 105 & 32.42 & 4.955 \\
\hline & Authoritative & 516 & 33.78 & 6.930 \\
\hline & Total & 1028 & 33.83 & 7.125 \\
\hline & Negligent & 326 & 7.85 & 2.717 \\
\hline & Permissive & 81 & 8.04 & 2.188 \\
\hline \multirow[t]{3}{*}{ Head Region Disorder } & Authoritarian & 105 & 7.63 & 1.750 \\
\hline & Authoritative & 516 & 7.66 & 2.093 \\
\hline & Total & 1028 & 7.75 & 2.287 \\
\hline
\end{tabular}




\section{Continued}

\begin{tabular}{lcccc}
\hline & Negligent & 326 & 11.85 & 3.373 \\
& Permissive & 81 & 11.80 & 2.537 \\
Alimentary Tract Disorder & Authoritarian & 105 & 11.16 & 2.398 \\
& Authoritative & 516 & 11.70 & 2.711 \\
& Total & 1028 & 11.70 & 2.899 \\
& Negligent & 326 & 17.08 & 4.623 \\
& Permissive & 81 & 16.94 & 4.445 \\
General Somatic Disorder & Authoritarian & 105 & 16.10 & 3.135 \\
& Authoritative & 516 & 17.25 & 4.046 \\
& Total & 1028 & 17.05 & 4.197 \\
& Negligent & 326 & 98.44 & 21.027 \\
& Permissive & 81 & 97.15 & 17.287 \\
General Psychopathology & Authoritarian & 105 & 92.70 & 13.560 \\
& Authoritative & 516 & 97.08 & 18.216 \\
& Total & 1028 & 97.07 & 18.729 \\
\hline
\end{tabular}

Table 4. One-way ANOVA showing the influence of parenting styles on psychopathological symptoms.

\begin{tabular}{|c|c|c|c|c|c|c|}
\hline & Source & SS & df & MS & $\mathbf{F}$ & $p$ \\
\hline \multirow{3}{*}{ Sleep Disorder } & Between Groups & 6.073 & 3 & 2.024 & 0.495 & $>0.05$ \\
\hline & Within Groups & 4189.826 & 1024 & 4.092 & & \\
\hline & Total & 4195.899 & 1027 & & & \\
\hline \multirow{3}{*}{ Intellect Disorder } & Between Groups & 7.487 & 3 & 2.496 & 1.094 & $>0.05$ \\
\hline & Within Groups & 2336.991 & 1024 & 2.282 & & \\
\hline & Total & 2344.479 & 1027 & & & \\
\hline \multirow{3}{*}{ Heat Disorder } & Between Groups & 147.079 & 3 & 49.026 & 4.153 & $<0.01$ \\
\hline & Within Groups & $12,088.153$ & 1024 & 11.805 & & \\
\hline & Total & $12,235.232$ & 1027 & & & \\
\hline \multirow{3}{*}{ Mood Disorder } & Between Groups & 323.398 & 3 & 107.799 & 2.130 & $>0.05$ \\
\hline & Within Groups & $51,816.470$ & 1024 & 50.602 & & \\
\hline & Total & $52,139.868$ & 1027 & & & \\
\hline \multirow{3}{*}{$\begin{array}{c}\text { Head Region } \\
\text { Disorder }\end{array}$} & Between Groups & 15.727 & 3 & 5.242 & 1.002 & $>0.05$ \\
\hline & Within Groups & 5357.007 & 1024 & 5.231 & & \\
\hline & Total & 5372.734 & 1027 & & & \\
\hline \multirow{3}{*}{ Alimentary Tract } & Between Groups & 38.559 & 3 & 12.853 & 1.531 & $>0.05$ \\
\hline & Within Groups & 8594.356 & 1024 & 8.393 & & \\
\hline & Total & 8632.914 & 1027 & & & \\
\hline \multirow{3}{*}{ General Somatic } & Between Groups & 114.903 & 3 & 38.301 & 2.181 & $>0.05$ \\
\hline & Within Groups & $17,979.364$ & 1024 & 17.558 & & \\
\hline & Total & $18,094.268$ & 1027 & & & \\
\hline \multirow{3}{*}{$\begin{array}{c}\text { General } \\
\text { Psychopathology }\end{array}$} & Between Groups & 2626.259 & 3 & 875.420 & 2.507 & $>0.05$ \\
\hline & Within Groups & $357,613.557$ & 1024 & 349.232 & & \\
\hline & Total & $360,239.816$ & 1027 & & & \\
\hline
\end{tabular}


However, no other mean score difference was observed. This implied that the observed significant influence in the ANOVA in Table 5 could be attributed to the difference between negligent and authoritarian parenting styles.

The results in Table 6 reveal that responsive and control parenting style jointly predicted sleep disorder $\left(\mathrm{R}^{2}=0.01, \mathrm{~F}(24,1025)=2.94, p<0.05\right)$. When combined, responsive and control parenting styles accounted for $1 \%$ of the change observed in the self-report of sleep disorder. The result further revealed that responsive parenting style $(\beta=0.14, \mathrm{t}=2.26, p<0.01)$ and control parenting style $(\beta=-0.15, \mathrm{t}=-2.39, p<0.01)$ independently predicted sleep disorder.

Responsive and control parenting style did not jointly predicted intellect disorder $\left(\mathrm{R}^{2}=0.00, \mathrm{~F}(2,1025)=2.25, p>0.05\right)$. When combined, responsive and

Table 5. Summary of post-hoc Scheffe test showing the mean difference of parenting styles on heat disorder.

\begin{tabular}{lcccc}
\hline \multicolumn{1}{c}{ Parenting Styles } & $\mathbf{1}$ & $\mathbf{2}$ & $\mathbf{3}$ & $\mathbf{4}$ \\
\hline 1. Negligent & - & & & \\
2. Permissive & 0.45 & - & & \\
3. Authoritarian & $1.36^{*}$ & 0.91 & - & \\
4. Authoritative & 0.37 & 0.08 & 0.99 & - \\
\hline
\end{tabular}

${ }^{\star}$ Mean difference is significant at 0.05 .

Table 6. Multiple regression showing the prediction of psychopathological symptoms by responsive and control parenting styles.

\begin{tabular}{|c|c|c|c|c|c|c|c|}
\hline Criterion & Predictors & $\beta$ & $\mathrm{T}$ & $\mathbf{R}$ & $\mathbf{R}^{2}$ & df & $\mathbf{F}$ \\
\hline \multirow{2}{*}{ Sleep Disorder } & Responsive Parenting Style & 0.14 & $2.26^{*}$ & \multirow{2}{*}{0.08} & \multirow{2}{*}{0.01} & \multirow{2}{*}{2,1025} & \multirow{2}{*}{$2.94^{\star}$} \\
\hline & Control Parenting Style & -0.15 & $-2.39^{*}$ & & & & \\
\hline \multirow{2}{*}{ Intellect Disorder } & Responsive Parenting Style & 0.08 & 1.27 & \multirow{2}{*}{0.07} & \multirow{2}{*}{0.00} & \multirow{2}{*}{2,1025} & \multirow{2}{*}{2.25} \\
\hline & Control Parenting Style & -0.12 & -1.96 & & & & \\
\hline \multirow[b]{2}{*}{ Heat Disorder } & Responsive Parenting Style & 0.21 & $3.41^{* *}$ & \multirow[b]{2}{*}{0.12} & \multirow[b]{2}{*}{0.02} & \multirow[b]{2}{*}{2,1025} & \multirow[b]{2}{*}{$7.80^{\star *}$} \\
\hline & Control Parenting Style & -0.24 & $-3.95^{\star *}$ & & & & \\
\hline \multirow{2}{*}{ Mood Disorder } & Responsive Parenting Style & 0.10 & 1.60 & \multirow{2}{*}{0.07} & \multirow{2}{*}{0.01} & \multirow{2}{*}{2,1025} & \multirow{2}{*}{2.47} \\
\hline & Control Parenting Style & -0.13 & $-2.16^{\star}$ & & & & \\
\hline \multirow{2}{*}{$\begin{array}{l}\text { Head Region } \\
\text { Disorder }\end{array}$} & Responsive Parenting Style & 0.12 & $2.03^{*}$ & \multirow{2}{*}{0.11} & \multirow{2}{*}{0.01} & \multirow{2}{*}{2,1025} & \multirow{2}{*}{$6.25^{* *}$} \\
\hline & Control Parenting Style & -0.20 & $-3.22^{\star *}$ & & & & \\
\hline \multirow{2}{*}{$\begin{array}{l}\text { Alimentary Tract } \\
\text { disorder }\end{array}$} & Responsive Parenting Style & 0.16 & $2.58^{*}$ & \multirow{2}{*}{0.11} & \multirow{2}{*}{0.01} & \multirow{2}{*}{2,1025} & \multirow{2}{*}{$5.69^{\star *}$} \\
\hline & Control Parenting Style & -0.20 & $-3.33^{* *}$ & & & & \\
\hline \multirow{2}{*}{$\begin{array}{c}\text { General Somatic } \\
\text { Disorder }\end{array}$} & Responsive Parenting Style & 0.18 & $2.95^{\star *}$ & \multirow{2}{*}{0.09} & \multirow{2}{*}{0.01} & \multirow{2}{*}{2,1025} & \multirow{2}{*}{$4.36^{*}$} \\
\hline & Control Parenting Style & -0.16 & $-2.55^{\star}$ & & & & \\
\hline \multirow{2}{*}{$\begin{array}{c}\text { General } \\
\text { Psychopathology }\end{array}$} & Responsive Parenting Style & 0.18 & $2.89^{* *}$ & \multirow{2}{*}{0.11} & 0.01 & 2.1025 & 597 \\
\hline & Control Parenting Style & -0.21 & $-3.45^{\star *}$ & & 0.01 & 2,1023 & (2.) \\
\hline
\end{tabular}

Note: ${ }^{* *} p<0.01,{ }^{*} p<0.05, \mathrm{~N}=1028$. 
control parenting style accounted for $0 \%$ of the change observed in intellect disorder. The result further revealed that responsive parenting style $(\beta=0.08, \mathrm{t}=$ $1.27, p>0.05)$ and control parenting style $(\beta=-0.12, \mathrm{t}=-1.96, p>0.05)$ were not significant independent predictors of intellect disorder. Moreso, responsive and control parenting style jointly predicted heat disorder $\left(\mathrm{R}^{2}=0.02, \mathrm{~F}(2,1025)\right.$ $=7.80, p<0.01)$. When combined, responsive and control parenting style accounted for $2 \%$ of the changes observed in heat disorder. The result further revealed that responsive parenting style $(\beta=0.21, \mathrm{t}=3.41, p<0.01)$ and control parenting style $(\beta=-0.24, \mathrm{t}=-3.95, p<0.01)$ were significant independent predictors of heat disorder. Table 6 further revealed that responsive and control parenting styles did not jointly predict mood disorder $\left(R^{2}=0.01, F(2,1025)=\right.$ 2.47, $p>0.05$ ). When combined, responsive and control parenting styles accounted for $1 \%$ of the change observed in the self-report of mood disorder. The result further revealed that control parenting style $(\beta=-0.13, \mathrm{t}=-3.22, p<$ $0.05)$ have a significant independent prediction on mood disorder while responsive parenting style $(\beta=0.10, t=1.60, p>0.05)$ did not significantly and independently predict mood disorder. More so, responsive and control parenting styles jointly predicted head region disorder $\left(\mathrm{R}^{2}=0.01, \mathrm{~F}(2,1025)=6.25, p<\right.$ $0.01)$. When combined, responsive and control parenting styles accounted for $1 \%$ of the change observed in the self-report of head region disorder. The result further revealed that responsive parenting style $(\beta=0.12, \mathrm{t}=2.03, p<0.05)$ and control parenting style $(\beta=-0.20, \mathrm{t}=-3.22, p<0.01)$ were significant independent predictors of head region disorder. In addition, responsive and control parenting styles jointly predicted alimentary tract disorder $\left(\mathrm{R}^{2}=0.01, \mathrm{~F}(2,1025)=\right.$ 5.69, $p<0.01)$. When combined, responsive and control parenting styles accounted for $1 \%$ of the change observed in the self-report of alimentary tract disorder. The result further revealed that responsive parenting style $(\beta=0.16, t=$ $2.58, p<0.05)$ and control parenting style $(\beta=-0.20, \mathrm{t}=-3.33, p<0.01)$ were significant independent predictors of alimentary. The test on the prediction of general somatic by parenting style revealed that responsive and control parenting styles jointly predicted general somatic disorder $\left(\mathrm{R}^{2}=0.01, \mathrm{~F}(2,1025)=4.36\right.$, $p<0.05)$. When combined, responsive and control parenting styles accounted for $1 \%$ of the change observed in the self-report of general somatic disorder. The result further revealed that responsive parenting style $(\beta=0.18, \mathrm{t}=2.95, p<$ $0.01)$ and control parenting style $(\beta=-0.16, \mathrm{t}=-2.55, p<0.05)$ were significant independent predictors of general somatic disorder.

Lastly, responsive and control parenting styles jointly predicted general psychopathology $\left(\mathrm{R}^{2}=0.01, \mathrm{~F}(2,1025)=4.36, p<0.01\right)$. When combined, responsive and control parenting styles accounted for $1 \%$ of the change observed in the self-report of general psychopathology. The result further revealed that responsive parenting style $(\beta=0.18, \mathrm{t}=2.89, p<0.01)$ and control parenting style $(\beta=$ $-0.21, \mathrm{t}=-3.45, p<0.01)$ were significant independent predictors of general psychopathology. 
The second hypothesis stated that there will be significant sex differences on psychopathological symptoms among in-school adolescents in Ogun state.

Table 7 shows that gender significantly influenced sleep disorder $[\mathrm{t}(1026)=$ 2.95; $p<0.01]$. The result indicated that male respondents significantly reported higher sleep disorder (Mean $=8.46 ; \mathrm{SD}=2.07$ ) compared to male respondents (Mean $=8.09 ; \mathrm{SD}=1.96)$. Also, Gender did not significantly influence intellect disorder $[\mathrm{t}(1026)=0.68 ; p>0.05]$. This implied that males (Mean $=5.43 ; \mathrm{SD}=$ 1.56) were not significantly different from females (Mean $=5.37 ; \mathrm{SD}=1.47$ ) when compared on mood disorder. Also, gender did not significantly influence heat disorder $[\mathrm{t}(1026)=1.44 ; p>0.05]$. This implied that males $($ Mean $=13.23$; $\mathrm{SD}=3.59)$ were not significantly different from females (Mean $=12.92$; $\mathrm{SD}=$ 3.31) when compared on heat disorder. Gender significantly influence mood disorder $[\mathrm{t}(1026)=2.33 ; p<0.05]$. The result indicated that male respondents reported higher mood disorder (Mean $=33.33 ; \mathrm{SD}=6.99)$ compared to female respondents (Mean $=33.33$; $\mathrm{SD}=6.99)$. It was also observed that; gender did not significantly influence head region disorder $[\mathrm{t}(1026)=-0.75 ; p>0.05]$. This means that male respondents (Mean $=7.80 ; \mathrm{SD}=2.37$ ) do not significantly differ compared to male respondents (Mean $=7.69 ; \mathrm{SD}=2.21$ ) in head region disorder. Gender significantly influence alimentary tract disorder $[\mathrm{t}(1026)=2.47 ; p$ $<0.05]$. The result indicated that male respondents reported higher alimentary tract disorder $($ Mean $=11.93 ; \mathrm{SD}=3.00)$ compared to female respondents

Table 7. T-test summary table showing sex difference on psychopathological symptoms among the participants.

\begin{tabular}{|c|c|c|c|c|c|c|c|}
\hline & Gender & $\mathbf{N}$ & $\bar{X}$ & SD & DF & $\mathbf{t}$ & Sig \\
\hline \multirow{2}{*}{ Sleep disorder } & Male & 498 & 8.46 & 2.07 & 1026 & 2.95 & $<0.01$ \\
\hline & Female & 530 & 8.09 & 1.96 & & & \\
\hline \multirow{2}{*}{ Intellectual disorder } & Male & 498 & 5.43 & 1.56 & 1026 & 0.68 & $>0.05$ \\
\hline & Female & 530 & 5.37 & 1.47 & & & \\
\hline \multirow[t]{2}{*}{ Heat disorder } & Male & 498 & 13.23 & 3.59 & 1026 & 1.44 & $>0.05$ \\
\hline & Female & 530 & 12.92 & 3.31 & & & \\
\hline \multirow[t]{2}{*}{ Mood disorder } & Male & 498 & 34.36 & 7.24 & 1026 & 2.33 & $<0.05$ \\
\hline & Female & 530 & 33.33 & 6.99 & & & \\
\hline \multirow[t]{2}{*}{ Head region disorder } & Male & 498 & 7.80 & 2.37 & 1026 & 0.75 & $>0.05$ \\
\hline & Female & 530 & 7.69 & 2.21 & & & \\
\hline \multirow[t]{2}{*}{ Alimentary tract disorder } & Male & 498 & 11.93 & 3.00 & 1026 & 2.47 & $<0.05$ \\
\hline & Female & 530 & 11.49 & 2.78 & & & \\
\hline \multirow[t]{2}{*}{ General somatic disorder } & Male & 498 & 17.21 & 4.48 & 1026 & 1.21 & $>0.05$ \\
\hline & Female & 530 & 16.90 & 3.91 & & & \\
\hline \multirow[t]{2}{*}{ General psychopathology } & Male & 498 & 98.44 & 19.10 & 1026 & 2.27 & $<0.05$ \\
\hline & Female & 530 & 95.79 & 18.30 & & & \\
\hline
\end{tabular}


$($ Mean $=11.49 ; \mathrm{SD}=2.78)$. In addition, gender did not significantly influence general somatic disorder $[\mathrm{t}(1026)=1.21 ; p>0.05]$. This means that male respondents $($ Mean $=17.21 ; \mathrm{SD}=4.48)$ were not significantly different from female respondents $($ Mean $=16.90 ; \mathrm{SD}=3.91)$ when compared on general somatic disorder. Finally, gender significantly influenced general psychopathology $[\mathrm{t}(1026)$ $=2.27 ; p<0.05]$. The result indicated that male respondents reported higher general psychopathology $($ Mean $=98.44$; $\mathrm{SD}=19.10)$ compared to female respondents $($ Mean $=95.79 ; \mathrm{SD}=18.30)$.

The third hypothesis stated that there would be a significant influence of family type on psychopathological symptoms among in-school adolescents in Ogun state.

The results presented in Table 8 shows that student from monogamous family setting $(M=8.15$, S.D = 2.10) significantly reported lower scores on sleep disorder than those from polygamous family settings $(M=8.60, S . D=1.75)$. The result demonstrates that there was a significant difference in the mean score of sleep disorder reported by adolescents from monogamous and polygamous family settings $(\mathrm{t}(1026)=-3.17, p<0.05)$. Participants from monogamous family setting $(M=5.35, S . D=1.55)$ were not significantly different in the intellectual disorder than those from polygamous family settings $(M=5.53$, S.D $=1.38)$. The result demonstrates that there was no significant difference in the intellectual disorder reported by adolescent from monogamous and polygamous family setting $(\mathrm{t}(1026)=-1.68, p>0.05)$. Table 8 further shows that participants from

Table 8. Independent t-test showing difference in psychopathological symptoms based on family type.

\begin{tabular}{|c|c|c|c|c|c|c|c|}
\hline Psychopathological Symptoms & Family Type & $\mathrm{N}$ & Mean & $\mathrm{SD}$ & Df & $\mathrm{t}$ & $p$ \\
\hline \multirow[b]{2}{*}{ Sleep Disorder } & Monogamous & 757 & 8.15 & 2.097 & \multirow[b]{2}{*}{1026} & \multirow[b]{2}{*}{-3.17} & \multirow[b]{2}{*}{$<0.01$} \\
\hline & Polygamous & 271 & 8.60 & 1.754 & & & \\
\hline \multirow{2}{*}{ Intellect Disorder } & Monogamous & 757 & 5.35 & 1.554 & \multirow{2}{*}{1026} & \multirow{2}{*}{-1.68} & \multirow{2}{*}{$>0.05$} \\
\hline & Polygamous & 271 & 5.53 & 1.379 & & & \\
\hline \multirow{2}{*}{ Heat Disorder } & Monogamous & 757 & 12.93 & 3.567 & \multirow{2}{*}{1026} & \multirow{2}{*}{-2.25} & \multirow{2}{*}{$<0.05$} \\
\hline & Polygamous & 271 & 13.48 & 3.077 & & & \\
\hline \multirow{2}{*}{ Mood Disorder } & Monogamous & 757 & 33.50 & 7.184 & \multirow{2}{*}{1026} & \multirow{2}{*}{-2.47} & \multirow{2}{*}{$<0.05$} \\
\hline & Polygamous & 271 & 34.75 & 6.889 & & & \\
\hline \multirow[b]{2}{*}{ Head Region Disorder } & Monogamous & 757 & 7.65 & 2.317 & \multirow[b]{2}{*}{1026} & \multirow[b]{2}{*}{-2.35} & \multirow[b]{2}{*}{$<0.05$} \\
\hline & Polygamous & 271 & 8.03 & 2.181 & & & \\
\hline \multirow{2}{*}{ Alimentary Tract disorder } & Monogamous & 757 & 11.60 & 2.975 & \multirow{2}{*}{1026} & \multirow{2}{*}{-1.85} & \multirow{2}{*}{$>0.05$} \\
\hline & Polygamous & 271 & 11.98 & 2.660 & & & \\
\hline \multirow[b]{2}{*}{ General Somatic disorder } & Monogamous & 757 & 16.92 & 4.272 & \multirow[b]{2}{*}{1026} & \multirow[b]{2}{*}{-1.64} & \multirow[b]{2}{*}{$>0.05$} \\
\hline & Polygamous & 271 & 17.41 & 3.967 & & & \\
\hline \multirow{2}{*}{ General Psychopathology } & Monogamous & 757 & 96.10 & 19.095 & \multirow{2}{*}{1026} & \multirow{2}{*}{-2.78} & \multirow{2}{*}{$<0.01$} \\
\hline & Polygamous & 271 & 99.77 & 17.415 & & & \\
\hline
\end{tabular}


monogamous family setting $(M=12.93, S . D=3.57)$ significantly reported lower scores on heat disorder than those from polygamous family settings $(M=13.48$, S.D $=3.08)$. The result demonstrates that there was a significant difference in the heat disorder reported by participants from monogamous and polygamous family setting $(\mathrm{t}(1026)=-2.25, p<0.05)$.

In addition, students from polygamous family setting $(M=34.75, S . D=6.89)$ significantly reported higher scores on mood disorder compared to those from monogamous family setting $(\mathrm{M}=33.50$, S.D = 7.18). The result demonstrates that there was a significant difference in the mood disorder reported by participants from monogamous and polygamous family setting $(\mathrm{t}(1026)=-2.47, p<$ 0.05).

Moreover, participants from monogamous family setting $(\mathrm{M}=7.65$, S.D $=$ 2.32) significantly reported lower scores on head region disorder than those from polygamous family settings $(M=8.03$, S.D = 2.18). The result demonstrates that there was significant difference in the head region disorder reported by adolescents from monogamous and polygamous family setting $(\mathrm{t}(1026)=$ $-2.35, p<0.05)$.

Adolescents from monogamous family setting $(M=11.60, \mathrm{~S} . \mathrm{D}=2.98)$ were not significantly different in the alimentary tract disorder than those from polygamous family settings $(M=11.98, S . D=2.66)$. The result shows that there was no significant difference in the alimentary tract disorder reported by participants from monogamous and polygamous family settings $(\mathrm{t}(1026)=-1.85, p>0.05)$.

Furthermore, adolescents from monogamous family setting $(\mathrm{M}=16.92, \mathrm{~S} . \mathrm{D}=$ 4.27) were not significantly different in the level of general somatic compared to those from polygamous family setting $(M=17.41$, S.D = 3.97). The result demonstrates that there was no significant difference in the general somatic reported by adolescents from monogamous and polygamous family setting $(\mathrm{t}(1026)=-1.64, p>0.05)$.

Finally, adolescents from monogamous family setting $(\mathrm{M}=96.10, \mathrm{~S} . \mathrm{D}=$ 19.10) reported significantly lower scores on general psychopathology than those from polygamous family settings $(M=99.77, \mathrm{~S} . \mathrm{D}=17.42)$. The result demonstrates that there was significant difference in the general psychopathology reported by adolescents from monogamous and polygamous family setting $(\mathrm{t}(1026)=-2.35, p<0.05)$. The result demonstrates that family type significantly influence the level of general psychopathology among the student sampled.

\section{Discussions}

Findings from the study revealed a high prevalence of psychopathological symptoms among the participants. This result supports a similar study by Onisile et al. (2020). They found a 92.7\% prevalence of psychopathological symptoms among a sample of 496 secondary school adolescents in Ede metropolis Osun State Nigeria. Akpunne (2015) also reported a 35.4\% prevalence of psychological distress among secondary school students in Ogun state Nigeria. In a later study, Akpunne and Akinnawo (2017) reported a 58.7\% prevalence of psy- 
chological distress among adolescents in correctional facilities in Lagos, Nigeria.

The study also reveals that parenting style had no influence on psychopathological symptoms among adolescents. However, the responsiveness and control dimension of parenting predicted psychopathological symptoms among the respondents. This finding is supported Rezvan and D'Souza (2017), who found out that Parenting styles did not have a significant influence on the mental health of the adolescents in somatic symptoms, anxiety, social dysfunction, depression and total scores. However, the finding of this study contradicts a study conducted on children of Japan (Uji et al., 2014) that showed a positive impact of authoritative, authoritarian, and permissive parenting styles on children's later mental health. Zare et al. (2014) also reported a significant positive relationship between parenting style and general health.

The result showed that sex significantly influences psychopathological symptoms, with the male responding with higher psychological symptoms than the females. This finding is in line with Hagen and Rosenstrom (2016), who reported that sex is a significant predictor of psychopathologies. However, the result contrasts with a study by Van Droogenbroeck, Spruyt, and Keppens (2018), who concluded that both male and female adolescents report psychopathological problems. Therefore, it is suggestive that building a robust social support system for these adolescents may serve as a protective buffer against psychopathology among adolescents.

The study also revealed that family type significantly influenced psychopathological symptoms among adolescents. Adolescents from polygamous family settings were observed to report higher psychopathological symptoms than monogamous families. This finding is consistent with the outcome of a study by (Al-Krenawi, \& Slonim-Nevo, 2008) when they found out that those who grew up in monogamous families had better mental health than those raised in polygamous families. Polygamy family structure affects the relationship between marriage partners and the relationship between parents (especially the father) and children. The effects of poor relationships between polygamous marriage partners negatively affected adolescents (Al-Shamsi \& Fulcher, 2005). Also, in his study, Al-Sharfi et al. (2015) found out that adolescents from polygamous families had higher depression, bullying, and victimization scores than adolescents from monogamous families.

\section{Conclusion and Recommendations}

There is a high prevalence of psychopathological symptoms (intellectual and heat disorder) among Nigerian in-school adolescents. Parenting styles are a significant predictor of psychopathological symptoms among Nigerian secondary school adolescents. Sex and family type significantly influence the manifestation of psychopathological symptoms among in-school adolescents in Nigeria. Authors recommend a balance between control parenting styles and responsive parenting style as this will have a long-lasting positive influence on the psycholog- 
ical health of in-school adolescents.

Furthermore, parents of in-school adolescents should be psycho-educated on parenting styles and their effect on the psychological health of their wards. There is a need for governmental and non-governmental organizations to embark on a general public sensitization and awareness of parenting style influence on adolescent mental health. Policies on the establishments of psychological services department in Nigerian schools should be monitored and properly executed. These services would offer some psychological first aid and psycho-behavioural interventions to adolescents observed to manifest some psychopathologies. Such interventions should mutate into family therapies once severe cases are precipitated, predisposed or perpetuated by poor parenting factors. Lastly, further studies on the influence of the extraneous variables such as characteristics of adolescents viz: relationships with the opposite sex, sports activity, psychopathological conditions that may have existed before and are due to heredity or traumatic experiences not due to parenting style, and economic background of the family are recommended.

\section{Limitations of the Study}

This study focuses on the influence of parenting styles on psychopathological symptoms of In-school Nigerian adolescents. The influence of the extraneous variables such as characteristics of the sample adolescents (e.g. relationships with the opposite sex, sports activity, psychopathological conditions that may have existed before and were due to heredity or traumatic experiences not due to parenting style, and economic background of the family) were not assessed in this study.

\section{Conflicts of Interest}

None is declared by the authors.

\section{References}

Abdul Gafoor, K., \& Kurukkan, A. (2014). Construction and Validation of the Scale of Parenting Style. Guru Journal of Behavioral and Social Sciences, 2, 315-323.

Akinnawo, E. O. (1990). Further Validational Study of the Awaritefe Psychological Index (Form C) a Content-Oriented Approach. Unpublished Seminar Paper, Ondo State University, Ado Ekiti.

Akinnawo, E. O., \& Ofovwe, C. (2012). A Validational Study of API-Form X on Nigerian Adolescents. IFE Psychologia, 20, 41.

Akpunne, B. C. (2015). Prevalence and Nature of Child Neglect and Mental Health Status of Secondary School Adolescents. Advances in Social Science Research Journal, 2, 233-247. https://doi.org/10.14738/assrj.24.1022

Akpunne, B. C., \& Akinnawo E. O. (2017). Domestic Violence Influence on Psychological Distress among Institutionalized Adolescents. International Journal of Research in Economics and Social Sciences, 7(8).

Al-Krenawi, A., \& Slonim-Nevo, V. (2008). The Psychosocial Profile of Bedouin Arab 
Women Living in Polygamous and Monogamous Marriages. Families in Society, 89, 139-149. https://doi.org/10.1606/1044-3894.3718

Al-Shamsi, M., \& Fulcher, L. (2005). The Impact of Polygamy on United Arab Emirates' First Wives and Their Children. International Journal of Child \& Family Welfare, 1, 46-55.

AL-Sharfi, M., Pfeffer, K., \& Miller, K. A. (2015). The Effects of Polygamy on Children and Adolescents: A Systematic Review. Journal of Family Studies, 22, 272-286. https://doi.org/10.1080/13229400.2015.1086405

Awaritefe, A., Ofovwe, C. E., \& Madu, S. N. (2010). Evaluation of Psychopathological Patterns among Students of Two African Universities. African Journal for Psychological Study of Social Science, 13. https://www.ajol.info/index.php/ajpssi/article/view/60733

Awaritefe, A. A. (1982). The Awaritefe Psychological Index. Nigerian Journal of Clinical Psychology, 1, 42-51.

Baumrind, D. (1991). The Influence of Parenting Style on Adolescent Competence and Substance Abuse. Journal of Early Adolescence, 11, 56-95.

https://doi.org/10.1177/0272431691111004

Bolghan-Abadi, M., Kimiaee, S.-A., \& Amir, F. (2011). The Relationship between Parents' Child Rearing Styles and Their Children's Quality of Life and Mental Health. Psychology, 2, 230-234. https://doi.org/10.4236/psych.2011.23036

Bowlby, J. (1969). Attachment and Loss, Vol. 1: Attachment. Attachment and Loss. New York: Basic Books.

Bowlby, J. (1980). Attachment and Loss, Vol. 3: Loss, Sadness and Depression. New York: Basic Books.

Brooks, F. M., Magnusson, J., Spencer, N., \& Morgan, A. (2012). Adolescent Multiple Risk Behaviour: An Asset Approach to the Role of Family, School and Community. Journal of Public Health, 34, 48-56. https://doi.org/10.1093/pubmed/fds001

Hagen, H. E., \& Rosenström, T. (2016). Explaining the Sex Difference in Depression with a Unified Bargaining Model of Anger and Depression. Evolution, Medicine, and Public Health, 2016, 117-132. https://doi.org/10.1093/emph/eow006

Folkehelseinstituttet (2014). Psykiske lidelser hos barn og unge. Research Report 4. http://www.fhi.no/artikler/?id=110703

International Health Conference (1946). Constitution of the World Health Organization. Bulletin of the World Health Organization, 80, 983-984.

Kolappa, K., Henderson, D. C., \& Kishore, S. P. (2013). No Physical Health without Mental Health: Lessons Unlearned? Bulletin of the World Health Organization, 91, 3. https://doi.org/10.2471/BLT.12.115063

Li, Z., Wang, L., \& Zhang, L. (2012). Exploratory and Confirmatory Factor Analysis of a Short-Form of the EMBU among Chinese Adolescents. Psychological Reports, 110, 263-275. https://doi.org/10.2466/02.08.09.21.PR0.110.1.263-275

Maccoby, E. E., \& Martin, J. A. (1983). Socialization in the Context of the Family: Parent-Child Interaction. In P. H. Mussen (Series Ed.), \& E. M. Hetheringtono (Vol. Ed.), Handbook of Child Psychology. Vol. IV. Socialization, Personality and Social Development (4th ed., pp. 1-101). New York: Wiley.

Nakash-Eisikovits, O. R. A., Dutra, L., \& Westen, D. (2002). Relationship between Attachment Patterns and Personality Pathology in Adolescents. Journal of the American Academy of Child \& Adolescent Psychiatry, 41, 1111-1123.

https://doi.org/10.1097/00004583-200209000-00012 
Nelson, L. J., Padilla-Walker, L. M., Christensen, K. J., Evans, C. A., \& Carroll, J. S. (2011). Parenting in Emerging Adulthood: An Examination of Parenting Clusters and Correlates. Journal of Youth and Adolescence, 40, 730-743. https://doi.org/10.1007/s10964-010-9584-8

Onisile, D. O., Akpunne, B. C., \& Alakija, O. A. (2020). Psychoactive Substance and Psychopathological Symptoms among Nigerian Secondary Schools Adolescents. International Neuropsychiatric Disease Journal, 13, 1-10. https://doi.org/10.9734/indj/2019/v13i3-430114

Polanczyk, G. V., Salum, G. A., Sugaya, L. S., Caye, A., \& Rohde, L. A. (2015). Annual Research Review: A Meta-Analysis of the Worldwide Prevalence of Mental Disorders in Children and Adolescents. Journal of Child Psychology and Psychiatry, 56, 345-365. https://doi.org/10.1111/jcpp.12381

Rezvan, A., \& D’Souza, L. (2017). Influence of Parenting Styles on Mental Health of Adolescents. European Online Journal of Natural and Social Sciences, 6, 667-673.

Ruchkin, V. V., Eisemann, M., Koposov, R. A., \& Hägglöf, B. (2000). Family Functioning, Parental Rearing and Behavioural Problems in Delinquents. Clinical Psychology \& Psychotherapy, 7, 310-319. https://doi.org/10.1002/1099-0879(200010)7:4<310::AID-CPP264>3.0.CO;2-P

Spera, C. (2005). A Review of the Relationship among Parenting Practices, Parenting Styles, and Adolescent School Achievement. Educational Psychology Review, 17, 125-146. https://doi.org/10.1007/s10648-005-3950-1

Uji, M, Sakamoto, A., Adachi, K., \& Kitamura, T. (2014). The Impact of Authoritative, Authoritarian, and Permissive Parenting Styles on Children's Later Mental Health in Japan: Focusing on Parent and Child Gender. Journal of Child and Family Studies, 23, 293-302. https://doi.org/10.1007/s10826-013-9740-3

Van Droogenbroeck, F., Spruyt, B., \& Keppens, G. (2018). Gender Differences in Mental Health Problems among Adolescents and the Role of Social Support: Results from the Belgian Health Interview Surveys 2008 and 2013. BMC Psychiatry, 18, Article No. 6. https://doi.org/10.1186/s12888-018-1591-4

Verhoeven, M., Bögels, S. M., \& van der Bruggen, C. C. (2012). Unique Roles of Mothering and Fathering in Child Anxiety; Moderation by Child's Age and Gender. Journal of Child and Family Studies, 21, 331-343. https://doi.org/10.1007/s10826-011-9483-y

You, S., \& Lim, S. A. (2015). Development Pathways from Abusive Parenting to Delinquency: The Mediating Role of Depression and Aggression. Child Abuse \& Neglect, 46, 152-162. https://doi.org/10.1016/j.chiabu.2015.05.009

Zare, F., Bakhshipour, B., \& Hassanzadeh, R. (2014). Parenting Style and Mental Health in Iranian Adolescents. Journal of Novel Applied Sciences, 3, 274-277.

Patel, V., \& Rahman, A. (2015). Editorial Commentary: An Agenda for Global Child Mental Health. Child and Adolescent Mental Health, 20, 3-4.

Resnick, M. D., Bearman, P. S., Blum, R. W., Bauman, K. E., Harris, K. M., Jones, J., Tabor, J., Beuhring, T., Sieving, R. E., Shew, M., Ireland, M., Bearinger, L.H., \& Udry, J. R. (1997). Protecting Adolescents from Harm: Findings from the National Longitudinal Study on Adolescent Health. Journal of the American Medical Association, 278, 823-832.

Chen, P., \& Harris, K. M. (2019). Association of Positive Family Relationships with Mental Health Trajectories from Adolescence to Midlife. JAMA Pediatrics, 173, e193336.

Landstedt, E., Hammarström, A., \&Winefield, H. (2015). How Well Do Parental and Peer Relationships in Adolescence Predict Health in Adulthood? Scandinavian Journal of Public Health, 43, 460-468. 